\title{
Mothers' Knowledge of Health Caring for Premature Infants after Discharge from Neonatal Intensive Care Units in the Gaza Strip, Palestine
}

\author{
Ali Aldirawi1', Ali El-Khateeb², Ayman Abu Mustafa3 ${ }^{3}$, Samer Abuzerr ${ }^{4,5 *}$ \\ ${ }^{1}$ Neonatal Intensive Care Unit, Al-Shifa Hospital, Ministry of Health, Gaza, Palestine \\ ${ }^{2}$ Department of Nursing, University College of Applied Science, Gaza, Palestine \\ ${ }^{3}$ Palestine College of Nursing, Ministry of Health, Gaza, Palestine \\ ${ }^{4}$ Department of Environmental Health Engineering, School of Public Health, International Campus, Tehran University of Medical \\ Sciences, Tehran, Iran \\ ${ }^{5}$ Quality Improvement and Infection Control Unit, Ministry of Health, Gaza, Palestine \\ Email: mr_ali_90@hotmail.com, aymanayman20092009@hotmail.com, akhateeb@ucas.edu.ps, *samer_516@hotmail.com
}

How to cite this paper: Aldirawi, A., El-Khateeb, A., Mustafa, A.A. and Abuzerr, S. (2019) Mothers' Knowledge of Health Caring for Premature Infants after Discharge from Neonatal Intensive Care Units in the Gaza Strip, Palestine. Open Journal of Pediatrics, 9, 239-252. https://doi.org/10.4236/ojped.2019.93023

Received: September 4, 2019

Accepted: September 23, 2019

Published: September 26, 2019

Copyright $\odot 2019$ by author(s) and Scientific Research Publishing Inc. This work is licensed under the Creative Commons Attribution International License (CC BY 4.0).

http://creativecommons.org/licenses/by/4.0/

\begin{abstract}
Background: Preterm labor is one of the most public health problems related to neonates admitted to Neonatal Intensive Care Unit (NICU). Poor knowledge among mothers about the care requirements of a preterm neonate is immediate cause for post-discharge medical problems in premature and neonates readmission to NICU. Hence, this study aims to evaluate mothers' knowledge of caring for premature infants post-discharge from Neonatal Intensive Care Units in the Gaza strip. Methods: A Quantitative-based cross-sectional designs study was used to survey 120 mothers of preterm neonates at the time of preterm neonates discharge by face-to-face interview at Al-Shifa medical complex and Nasser hospital between February and June 2018. Results: The results showed that only about $58.4 \%$ of mothers of premature babies had good knowledge about health care needed for premature infants after discharge from NICU. Furthermore, there was no statistically significant difference between the level of knowledge and mother's sociodemographic characteristics ( $P$-values $>0.05)$. Conclusion: Mothers' knowledge of premature infants care was not at the optimal level, which might put the newborns at risk. Therefore, the study emphasizes the necessity of thoughtful exchange of health information between team members and mothers and establishing preand post-discharge plans with mothers to start their healthy transition of preterm neonate to home and to ameliorate family concerns.
\end{abstract}

\section{Keywords}

Mother's Knowledge, Preterm Neonates, Post-Discharge, Health Care, Neonatal 
Intensive Care Unit

\section{Background}

Premature birth is one that occurs before the start of the 37th week of pregnancy. Premature babies, especially those born very early, often have complicated medical problems leading admission to Neonatal Intensive Care Unit (NICU) [1]. The sensitivity of preterm stage lies in the development of body systems in this period, especially the nervous system consequently irrecoverable damage could be happening in this age [2]. Earlier research indicated that preterm neonate readmission to NICU due to jaundice, respiratory morbidities, temperature instability, hypoglycemia, and sepsis which may reach preterm neonatal death. The majority of infant morbidity and mortality are caused by parental unconsciousness, particularly insufficient maternal knowledge or misunderstanding of maternal and newborn care during this period. Thus, having a mother to necessary knowledge about health caring for premature infants after discharge from neonatal intensive care units is crucial [3].

Worldwide, 4 million newborns are dying in the first month of life, the vast majority of them from developing countries [4] [5]. While neonatal morbidity and mortality are multi-factorial, maternal awareness and training are among the most significant factors [6] [7].

The World Health Organization in 1988 has been issued the postnatal care recommendations focusing on preterm babies care in order to promote the mothers' knowledge in required preterm infants-related health care issues at home [8]. According to the Palestinian ministry of health reports, preterm neonates in 2016 accounted for $40.1 \%$ of NICUs admitted neonates [9]. In the Gaza strip, the infant mortality rate, which is the number of babies that die before they reach four weeks, reached 19.6 per 1000 live births [10]. Therefore, understanding the association between sociodemographic and economic factors affecting mothers' knowledge of health caring for premature infants post-discharge from neonatal intensive care units may be helpful in mitigating premature mortality and improve prognosis outcomes among them. To the best of our knowledge, this is the first study, which examined mothers' knowledge of health caring for premature infants after discharge from neonatal intensive care units and related-factors in the Gaza strip, Palestine.

\section{Materials and Methods}

\subsection{Study Design and Setting}

The current descriptive cross-sectional study was conducted in the main two NICUs which serve a vast portion of neonates in the Gaza strip between February and June 2018. The first located in Al-Shifa medical complex in Gaza governorate and the second situated in Nasser hospital in Khan Younis go- 
vernorate.

\subsection{Study Tool}

A twenty-one items structured questionnaire was used to gather information about sociodemographic characteristics and mother's knowledge about health caring for premature infants post-discharge from Neonatal Intensive Care Unit. The questionnaire was developed according to the previous literature review [11] [12] [13]. The questionnaire composed of three parts, the first part was dedicated to collect information regarding sociodemographic characteristics of the participant mothers whereas the second part was allocated to gather information about mothers education about premature infants health care post-discharge from NICU, and the third part investigates mothers knowledge concerning breastfeeding, infection prevention, vaccination, jaundice, temperature regulation, and umbilical cord care after discharge from NICU (Appendix 1). Content validity of the questionnaire was attained by five experts from different fields related to nursing, medicine, and public health. Afterward, the questionnaire was piloted among 15 mothers. Minor modifications were done after the pilot examination to guarantee its suitability and constancy. This internal consistency reliability of the questionnaire was computed statistically by Cronbach's alpha test which was over 0.7. Then, the questionnaire translated in Arabic language (mother tongue) in order to facilitate the responding of participants.

\subsection{Sample Size and Sampling Process}

According to the annual report issued by the Palestinian ministry of health [2], approximately thirty preterm neonates are discharged from the two selected NICUs every month. Since our study was conducted over five months, the study population is 150 mothers.

The representative sample size in the present study was calculated by the following formula [14].

$$
\text { Sample size }(n)=\frac{Z_{1-\alpha / 2}^{2} P(1-P)}{d^{2}}=\frac{(1.095)^{2}(0.50)(1-0.50)}{(0.05)^{2}}=120
$$

where, $Z_{1-\alpha / 2}=$ Standard normal variate $(Z$ value is 1.095 for a 95 percent confidence level). $p=$ Response distribution (50\%). $d=$ Margin of error (5\%).

The convenient sample size was 120 mothers of preterm neonates discharged from NICUs. Sixty mothers were selected from Al-Shifa medical complex while the other sixty mothers were selected from Nasser hospital. A face-to-face interview was carried out at the time of preterm neonates discharge. Data were collected by two qualified data collectors who were aware of the purpose of the study. The average time for filling the questionnaire was $10-15$ minutes.

\subsection{Eligibility Criteria}

The interview was carried out only in case of a mother with a preterm neonate 
will be discharged from NICU.

\subsection{Ethical Considerations}

The study protocol was approved by the Helsinki Ethical Committee in the Gaza Strip (Code: PHRC/HC/327/18). Written permission was sought and granted by the Palestinian ministry of health to conduct the study in NICUs at Al-Shifa medical complex and Nasser hospital. Likewise, mothers consent was gained after explaining the purpose of the study and they were not obliged to answer any questions which they did not like and were free to terminate the interview at any given time.

\subsection{Statistical Analysis}

The Statistical Package for Social Science (SPSS) version 22 was used for data analysis. Descriptive statistics of frequency and percentage, and mean and standard deviation were performed for categorical and continuous variables, respectively. The independent samples $t$-test was applied to investigate the differences between means. The chi-square test was used to determine the statistically significant differences between the different categorical variables.

\section{Results}

\subsection{Mothers' Sociodemographic Characteristics}

In this study, 120 mothers of preterm neonates who discharged from NICUs at Al-Shifa medical complex and Nasser hospital were enrolled. Almost $46.7 \%$ of the mothers were belonging to the age group 20 - 30 years. Most of the mothers (74.2\%) were housewives. The participated mothers were residing the five governorates of the Gaza strip as follows 11.7 from Rafah, 33.3\% from Khan Younis, 9.2\% were from the Middle area. 32.5\% from Gaza governorate and 13.3\% from the North Gaza governorate. Moreover, the surveyed mothers have distributed fifty-fifty percent to the two included NICUs. Around $74.2 \%$ of the mothers had less than 3 children whereas $25.8 \%$ had $4-7$ children. Fifty percent of surveyed mothers had a secondary education level and a small percentage (5.8\%) of mothers were living within households had monthly income more than 2000 New Israeli Shekel (NIS), the local currency (Table 1).

\subsection{Education of Mothers about Premature Infants Health Care Post-Discharge from NICU}

Almost $62.5 \%$ of study participants have received information concerning premature infant care post-discharge from NICU, $65 \%$ of those who received information revealed that nurses in NICU provided them with the needed information. About $85.3 \%$ received the education unilaterally not within a group of mothers. Only (30.8) of participants reported that they provided with a brochure explaining information about premature care post-discharge from NICU (Table 2). 


\subsection{Mothers' Knowledge of Health Caring for Premature Infants after Discharge from NICU}

The mean percentage of good knowledge of items related to breastfeeding was $54.2 \%$, Infection prevention was $73.3 \%$, vaccination was $60.2 \%$, jaundice was $67.1 \%$, temperature regulation was $50 \%$, and umbilical cord care was $46 \%$. Furthermore, the mean overall percentage of mothers' knowledge of health caring for premature infants after discharge from NICU was $58.4 \%$ (Table 3 ).

Table 1. Mothers' sociodemographic characteristics.

\begin{tabular}{|c|c|c|}
\hline Variables & Frequency (n) & Percentage (\%) \\
\hline \multicolumn{3}{|l|}{ Mother age groups (year) } \\
\hline$<20$ & 38 & 31.7 \\
\hline $20-30$ & 56 & 46.7 \\
\hline $31-40$ & 26 & 21.6 \\
\hline \multicolumn{3}{|l|}{ Mother employment status } \\
\hline Employed & 31 & 25.8 \\
\hline Housewife & 89 & 74.2 \\
\hline \multicolumn{3}{|l|}{ Governorate of residence } \\
\hline North Gaza & 16 & 13.3 \\
\hline Gaza & 39 & 32.5 \\
\hline Middle area & 11 & 9.2 \\
\hline Khan Younis & 40 & 33.3 \\
\hline Rafah & 14 & 11.7 \\
\hline \multicolumn{3}{|l|}{ Name of hospital } \\
\hline A,l-Shifa medical complex & 60 & 50.0 \\
\hline Nasser Hospital & 60 & 50.0 \\
\hline \multicolumn{3}{|l|}{ Number of children } \\
\hline$<3$ & 89 & 74.2 \\
\hline $4-7$ & 31 & 25.8 \\
\hline \multicolumn{3}{|l|}{ Education level } \\
\hline Primary & 15 & 12.5 \\
\hline Secondary & 60 & 50.0 \\
\hline University & 45 & 37.5 \\
\hline \multicolumn{3}{|c|}{ Household monthly income (NIS) } \\
\hline$<1000$ & 68 & 56.7 \\
\hline $1000-2000$ & 45 & 37.5 \\
\hline$>2000$ & 7 & 5.8 \\
\hline
\end{tabular}

$1 \mathrm{USD} \approx 3.5$ NIS. 
Table 2. Mothers' education about premature infants health care post-discharge from NICU.

\begin{tabular}{lcc}
\hline Variables & Frequency (n) & Percentage (\%) \\
\hline Have you received information about premature care post-discharge from & NICU? \\
Yes & 75 & 62.5 \\
No & 45 & 37.5 \\
Physician & 33 & 44 \\
Nurse & 42 & 65 \\
If yes, who provided you with the information? & & \\
Unilateral & 64 & 85.3 \\
How the information was given? & 11 & 14.7 \\
Within a group of mothers & & \\
Have you been provided with a brochure explaining information about premature care \\
post-discharge from NICU?
\end{tabular}

Table 3. Mothers' knowledge of health caring for premature infants after discharge from NICU.

\begin{tabular}{lll}
\hline Variables & Yes & No \\
& $\mathrm{n}(\%)$ & $\mathrm{n}(\%)$ \\
\hline
\end{tabular}

\section{Breastfeeding}

You must awaken your baby at breastfeeding time

Breast milk digests faster than formula

$97(80.8) \quad 23(19.2)$

Colostrum has many benefits for your newborn immune system

$92(66.7) \quad 28(33.3)$

Most newborns with jaundice can continue breastfeeding

$91(65.8) \quad 29(34.2)$

Premature infants who breast-feed may need iron and vitamin supplements

$40(33.3) \quad 80(66.7)$

Breastfeeding helps defend against infections, prevent allergies, and protect against a number of chronic conditions

$70(58.3) \quad 50(41.7)$

Keeping your newborn upright for 20 to 30 minutes after feeding will give his tummy time to settle and reduce feeding intolerances

Most newborn breastfeeding sessions take 20 to 45 minutes

$56(46.7) \quad 64(53.3)$

A newborn can go for 2 - 3 hours without the need to feed

\section{Infection prevention}

Cleanliness around newborns makes sense because newborn babies' immune systems aren't fully developed

\section{Vaccination}

Preterm babies should be vaccinated according to the recommended schedule, without correction for prematurity 


\section{Continued}

Jaundice

When a newborn baby shows signs of jaundice, the doctor performs a physical examination and blood tests to help determine the cause and treatment

When severe jaundice goes untreated for too long, it can cause a condition of brain damage

Mean percentage

Temperature regulation

Keeping your home warm enough and making sure the newborn is dressed right is necessary

Mean percentage

Umbilical cord care

Keep the stump dry, sticking with sponge baths, and letting the stump fall off on its own is necessary

Signs of infection and active bleeding of the umbilical cord stump can result in omphalitis

Mean percentage

\subsection{The Association between Mothers' Socio-Demographic Variables and Knowledge Level Regarding Preterm Health Care Post-Discharge from NICU}

Unexpectedly, the results revealed that there were no significant associations between mother's sociodemographic characteristics and education of mothers about premature infants health care post-discharge from NICU and their knowledge about preterm care after discharge from NICU ( $P$-values $>0.05)$ (Table 4).

\section{Discussion}

The mean overall percentage of mothers' knowledge of health caring for premature infants after discharge from NICU was $58.4 \%$. Even though our result exceeded the fifty percent, the fact that premature infants are vulnerable group, accordingly level of mothers' knowledge of health care for premature infants post-discharge from NICU in this study looks unacceptable. A similar conclusion was drawn by Adib-Hajbaghery and his colleague (2017) as the total score about knowledge of mothers about post-discharge newborn care in Shahid Beheshti Hospital of Kashan, Iran was 63\% [11]. Consistent findings also found by Akimana (2017) study which showed that the mean overall percentage of mothers awareness on the care of their preterm infant at discharge from a neonatal intensive care unit in a selected referral hospital in the northern province of Rwanda was 57.3\% [12]. A study to assess the knowledge of mothers on home-based neonatal care at a selected area of rural Bangalore as well indicated that only $14.2 \%$ of mothers had adequate knowledge on home-based neonatal care [13]. Besides, their outcomes indicated the need for founding plans to 
Table 4. The association between mother's sociodemographic associations and their knowledge about preterm care after discharge from NICU.

\begin{tabular}{|c|c|c|c|c|}
\hline Variables & $\mathbf{N}$ & Mean (SD) & $F(d f)$ & $P$-Value ${ }^{\star}$ \\
\hline \multicolumn{5}{|l|}{ Mother age groups (year) } \\
\hline$<20$ & 38 & $52.63(10.09)$ & \multirow{3}{*}{$0.231(2,117)$} & \multirow{3}{*}{0.794} \\
\hline $20-30$ & 56 & $51.50(10.70)$ & & \\
\hline $31-40$ & 26 & $53.03(11.32)$ & & \\
\hline \multicolumn{5}{|l|}{ Mother employment status } \\
\hline Employed & 31 & $52.29(10.86)$ & \multirow{2}{*}{$0.060(118)$} & \multirow{2}{*}{0.952} \\
\hline Housewife & 89 & $52.15(10.54)$ & & \\
\hline \multicolumn{5}{|l|}{ Governorate of residence } \\
\hline North Gaza & 39 & $51.95(9.89)$ & \multirow{5}{*}{$0.686(4,115)$} & \multirow{5}{*}{0.603} \\
\hline Gaza & 16 & $50.98(14.41)$ & & \\
\hline Middle area & 11 & $49.28(12.51)$ & & \\
\hline Khan Younis & 40 & $54.21(10.12)$ & & \\
\hline Rafah & 14 & $50.75(10.44)$ & & \\
\hline \multicolumn{5}{|l|}{ Name of hospital } \\
\hline Al-Shifa medical complex & 60 & $51.14(10.57)$ & \multirow{2}{*}{$-1.090(118)$} & \multirow{2}{*}{0.278} \\
\hline Naaser Hospital & 60 & $53.24(53.24)$ & & \\
\hline \multicolumn{5}{|l|}{ Number of children } \\
\hline$<3$ & 89 & $52.09(10.43)$ & \multirow{2}{*}{$-0.164(118)$} & \multirow{2}{*}{0.870} \\
\hline $4-7$ & 31 & $52.46(11.16)$ & & \\
\hline \multicolumn{5}{|l|}{ Education level } \\
\hline Primary & 15 & $54.38(10.65)$ & \multirow{3}{*}{$1.548(2,117)$} & \multirow{3}{*}{0.217} \\
\hline Secondary & 60 & $53.24(9.79)$ & & \\
\hline University & 45 & $50.05(11.42)$ & & \\
\hline \multicolumn{5}{|c|}{ Household monthly income (NIS) } \\
\hline$<1000$ Shekel & 68 & $53.32(10.04)$ & \multirow{3}{*}{$2.414(2,117)$} & \multirow{3}{*}{0.094} \\
\hline 1000 - 2000 Shekel & 45 & $51.69(11.12)$ & & \\
\hline$>2000$ Shekel & 7 & $44.36(10.01)$ & & \\
\hline
\end{tabular}

Receiving information about premature care post-discharge from NICU

$\begin{array}{lllll}\text { Yes } & 75 & 51.22(10.81) & & \\ \text { No } & 45 & 53.80(10.09) & & \\ & & & \end{array}$

Information Provider

$\begin{array}{cllll}\text { Physician } & 33 & 83.91(2.98) & & \\ \text { Nurse } & 42 & 85.05(3.12) & & \\ & & & & \end{array}$

The way information providing

$\begin{array}{lllll}\text { Unilateral } & 64 & 84.46(3.01) & 0.403(2,117) & 0.669 \\ \text { a group of mothers } & 11 & 84.87(3.49) & & \end{array}$

Receiving a brochure explaining information about premature care post-discharge from NICU

\begin{tabular}{lllll} 
Yes & 37 & $51.77(10.26)$ & $-0.286(118)$ & 0.776 \\
No & 83 & $52.37(10.77)$ & & \\
\hline
\end{tabular}

${ }^{*}$ Independent sample $\mathrm{t}$ test. One USD $\approx 3.5$ NIS. 
launch a system of maternity training in all hospitals for all mothers about baby care pre- and post-natal.

Unexpectedly, in the current study revealed that there were no significant associations between mother's sociodemographic characteristics and education of mothers about premature infants health care post-discharge from NICU and their knowledge about preterm care after discharge from NICU. Nonetheless, a recent systematic review conducted by Mohini and Shetty (2017) showed that mother's education, occupation, source of information had a highly significant relationship with their knowledge [13]. Nevertheless, family income of the mothers was not associated with their knowledge. The mother's knowledge, education, occupation, and source of information were significantly associated with their knowledge of home-based neonatal care. Furthermore, Adib-Hajbaghery and Khosrojerdi, (2017) reported that the mothers' education level, age, and place of residence could predict their knowledge of neonatal care [11]. Several studies have shown that mothers with more children have better knowledge about newborn care [15], however, Esmaeeli (2013) showed that mothers with 2 or 3 children had a higher level of knowledge comported those who had less than two children [16].

Previous research has stated that mothers' awareness about newborn care was improved by getting older [17] [18]. In addition, in the present study, mean percentage of good knowledge of items related to breastfeeding was $54.2 \%$, Infection prevention was $73.3 \%$, vaccination was $60.2 \%$, jaundice was $67.1 \%$, temperature regulation was $50 \%$, and umbilical cord care was $46 \%$. A study in Sri Lanka explored the variables related with mothers awareness of newborn care among hospital-delivered mothers and revealed that though more than ninety percent of mothers were knew of the pros of breastfeeding, only $21 \%$ aware appropriate umbilical cord care [19]. In Adib-Hajbaghery and Khosrojerdi (2017), the majority of mothers were aware of the optimal means for newborn feeding, preventing post-feeding regurgitation, baby laying, the suitable time for supplementary nutrition, neonatal jaundice, and umbilical cord care. Nonetheless, two studies in Nigeria [20] and Turkey [21] have stated that most mothers were not aware of the appropriate neonatal jaundice care and management. Preceding studies in other countries showed that mothers may take care of their infants according to their improper beliefs or by consulting of their relatives without any medical consultation [21] [22]. Our finding regarding the lack of association between mothers' knowledge about post-discharge newborn care and their employment status was in agreement with a study conducted by Amolo et al., (2017) who found no significant difference in the level of knowledge among various employment categories [23]. Conversely, Esmaeeli (2013) found that the employed mother had a higher level of knowledge (60\%) compared with housewife mother (40\%) [16].

In our study, there was no significant difference between mothers who received health education and those who did not receive. This result could be ex- 
plained by the shortcoming of the current educational programs. Hence, the study emphasizes the necessity of thoughtful exchange of health information between team members and mothers and establishing pre- and post-discharge plans with mothers to start their healthy transition of the preterm neonate to home and to ameliorate family concerns. The findings of Amolo et al., (2017) were inconsistent with ours as he found that the majority of mothers who received health education had adequate knowledge about essential care [23].

The main strength of our study was it is being the first study conducting in the Gaza strip to assess the mother's knowledge of health care for premature infants after discharge from neonatal intensive care units. On the other hand, it also has some noteworthy limitations as many independent factors may affect the mother's knowledge were not studies. Hereafter, further future investigations including more potential confounding factors are recommended.

\section{Conclusion}

In this study, mothers' knowledge of health care for premature infants after discharge from neonatal intensive care units was not at the ideal level putting the newborns at risk. In spite of there were no significant associations between mother's sociodemographic characteristics and their knowledge about preterm care after discharge from NICU, we suggest founding a well-planned maternal education program to bridge the knowledge gap about preterm infants care and grantee the healthy transition of preterm neonate to home and to ameliorate family concerns.

\section{Acknowledgements}

The General Directorate of Human Resources Development in the Palestinian Ministry of Health and the NICUs at al Al-Shifa medical complex and Nasser hospital are appreciated for their cooperation and giving us this opportunity to conduct the study. Also, we are grateful to all the mothers who participated in this study.

\section{Conflicts of Interest}

The authors declare no conflicts of interest regarding the publication of this paper.

\section{References}

[1] WHO (2015) WHO Recommendations on Interventions to Improve Preterm Birth Outcomes. Highlights and Key Messages from the World Health Organization's 2015 Global Recommendations. World Health Organization.

https://www.who.int/reproductivehealth/publications/maternal_perinatal_health/pr eterm-birth-highlights/en/

[2] Debillon, T., Zupan, V., Ravault, N., Magnyc, J.-F. and Dehan, M. (2001) Development and Initial Validation of the EDIN Scale, a New Tool for Assessing Prolonged Pain in Preterm Infants. Archives of Disease in Childhood-Fetal and Neonatal Edi- 
tion, 85, 36-41. https://doi.org/10.1136/fn.85.1.F36

[3] Weiner, A., Billamay, S., Partridge, C. and Martinez, A.M. (2011) Antenatal Education for Expectant Mothers Results in Sustained Improvement in Knowledge of Newborn Care. Journal of Perinatology, 31, 92-97. https://doi.org/10.1038/jp.2010.108

[4] Ababa, A. (2003) Federal Democratic Republic of Ethiopia Ministry of Health. Postnatal Care, Ethiopia. https://www.africanchildinfo.net/clr/policy\%20per\%20country/ethiopia/ethiopia_n utrition_2003_en.pdf

[5] Hoque, M., Khan, H., Begum, A., Chowdhury, A. and Persson, L.A. (2011) Newborn Care Practices by the Mother/Care Givers and Their Knowledge about Signs of Sickness of Neonates. Bangladesh Journal of Child Health, 35, 90-96.

https://doi.org/10.3329/bjch.v35i3.10497

[6] Izugbara, C. (2016) Single Motherhood and Neonatal and Infant Mortality in Sierra Leone, Burkina Faso and Burundi. Public health, 135, 122-130.

https://doi.org/10.1016/j.puhe.2016.01.017

[7] Samuel, O. (2013) Infant Mortality in Nigeria: Assessing Knowledge of Predisposing Risk Factors among Mothers and Bacteriological Profile of the Weaning Foods. American Journal of Food and Nutrition, 13, 22-26.

[8] WHO. (2014) Recommendations on Postnatal Care of the Mother and Newborn. World Health Organization.

https://apps.who.int/iris/bitstream/handle/10665/97603/9789241506649_eng.pdf

[9] MOH (2016) Annual Health Report, Gaza Strip. Palestine. Ministry of Health. http://www.site.moh.ps/Content/Books/ZxRcynmiUofNqt66u4CrHRgmJR6Uv7z77 srjjIEAho6xnz5V3rgLTu_RhO7xf2j2VusNiIvWkjwp84yXHLdGleB97gKrHHI5iZ9oPJ25o wGEN.pdf

[10] WHO (2017) Recommendations on Interventions to Improve Preterm Birth Outcomes. Palestine. World Health Organization.

https://www.who.int/reproductivehealth/publications/maternal_perinatal_health/pr eterm-birth-guideline/en/

[11] Adib-Hajbaghery, M. and Khosrojerdi, Z. (2017) Knowledge of Mothers about Post-Discharge Newborn Care. Journal of Nursing and Midwifery Sciences, 4, 33-41. http://jnms.mazums.ac.ir/article-1-276-en.html

[12] Akimana, T. (2017) Mothers Awareness and Attitudes on the Care of Their Preterm Infant at Discharge from a Neonatal Intensive Care Unit in a Selected Referral Hospital in the North Province of Rwanda. Doctoral Dissertation, University of Rwanda, Kigali, Rwanda. http://dr.ur.ac.rw/handle/123456789/268

[13] Mohini, H. and Shetty, S. (2017) A Study to Assess the Knowledge of Mothers on Home Based Neonatal Care at Selected Area of Rural Bangalore. International Journal of Community Medicine and Public Health, 4, 1695-1700. https://doi.org/10.18203/2394-6040.ijcmph20171786

[14] Charan, J. and Biswas, T. (2013) How to Calculate Sample Size for Different Study Designs in Medical Research? Indian Journal of Psychological Medicine, 35, 121-126. https://doi.org/10.4103/0253-7176.116232

[15] Senarath, U., Fernando, N., Vimpani, G. and Rodrigo, I. (2007) Factors Associated with Maternal Knowledge of Newborn Care among Hospital-Delivered Mothers in Sri Lanka. Transactions of the Royal Society of Tropical Medicine and Hygiene, 101, 823-830. https://doi.org/10.1016/j.trstmh.2007.03.003 
[16] Esmaeeli, H. (2013) Knowledge Assessment of Neonatal Care among Postnatal Mothers. Iranian Journal of Neonatology, 4, 28-31.

[17] Esfandtari, R., Baghiani Moghadam, H., Khakshour, A., Faroughi, F. and Saeidi, M. (2014) Study of Maternal Knowledge and Attitude toward Exclusive Breast Milk Feeding (BMF) in the First 6 Months of Infant in Yazd-Iran. International Journal of Pediatrics, 2, 175-181.

[18] Padiyath, A., Bhat, V. and Ekambaram, M. (2010) Knowledge Attitiude and Practice of Neonatal Care among Postnatal Mothers. Current Paediatric Research, 14, 147-152.

http://www.biomedres.info/biomedical-research/knowledge-attitiude-and-practiceof-neonatal-care-among-postnatal-mothers.pdf

[19] Senarath, U., Fernando, D.N., Vimpani, G. and Rodrigo, I. (2007) Factors Associated with Maternal Knowledge of Newborn Care among Hospital-Delivered Mothers in Sri Lanka. Transactions of the Royal society of tropical medicine and hygiene, 101, 823-830. https://doi.org/10.1016/j.trstmh.2007.03.003

[20] Egube, A., Ofili, N., Isara, R. and Onakewhor, J.U. (2013) Neonatal Jaundice and Its Management: Knowledge, Attitude, and Practice among Expectant Mothers Attending Antenatal Clinic at University of Benin Teaching Hospital, Benin City, Nigeria. Nigerian Journal of Clinical Practice, 16, 188-194.

https://doi.org/10.4103/1119-3077.110147

[21] Aydin, D., Karaca Ciftci, E. and Karatas, H. (2014) Identification of the Traditional Methods of Newborn Mothers Regarding Jaundice in Turkey. Journal of Clinical Nursing, 23, 524-530. https://doi.org/10.1111/jocn.12150

[22] Sutcuoglu, S., Dursun, S., Halicioglu, O., et al. (2012) Evaluation of Maternal Knowledge Level about Neonatal Jaundice. The Journal of Maternal-Fetal \& Neonatal Medicine, 25, 1387-1389. https://doi.org/10.3109/14767058.2011.636095

[23] Amolo, L., Irimu, G. and Njai, D. (2017) Knowledge of Postnatal Mothers on Essential Newborn Care Practices at the Kenyatta National Hospital: A Cross Sectional Study. The Pan African Medical Journal, 28, 97. https://doi.org/10.11604/pamj.2017.28.97.13785 


\section{Appendix: Questionnaire}

Mothers' Sociodemographic Characteristics

Mother age groups (year)

$<20$
$20-30$
$31-40$

Mother employment status

Employed

Housewife

Governorate of residence

North Gaza

Gaza Middle area Khan Younis Rafah

Name of hospital

Al-Shifa medical complex

Nasser Hospital

Number of children

$<3$

$4-7$

Education level

Primary

Household monthly income (NIS)

$<1000$

$1000-2000$

$>2000$

Mothers' education about premature infants health care post-discharge from NICU

Have you received information about premature care post-discharge from NICU?

Yes

No

If yes, who provided you with the information?

Physician

Nurse

How the information was given?

Unilateral

Within a group of mothers

Have you been provided with a brochure explaining information about premature care post-discharge from NICU?

Yes

No

Mothers' knowledge concerning breastfeeding, infection prevention, vaccination, jaundice, temperature regulation, and umbilical cord care after discharge from NICU

Breastfeeding

You must awaken your baby at breastfeeding time

Yes $\quad$ No

Breast milk digests faster than formula

Yes No

Colostrum has many benefits for your newborn immune system

Yes No

Most newborns with jaundice can continue breastfeeding

Yes No

Premature infants who breast-feed may need iron and vitamin supplements Yes No

Breastfeeding helps defend against infections, prevent allergies, and protect Yes No against a number of chronic conditions

Keeping your newborn upright for 20 to 30 minutes after feeding will give his Yes No tummy time to settle and reduce feeding intolerances

Most newborn breastfeeding sessions take 20 to 45 minutes

Yes $\quad$ No 


\section{Continued}

A newborn can go for 2 - 3 hours without the need to feed

\section{Infection prevention}

Cleanliness around newborns makes sense because newborn babies' immune Yes systems aren't fully developed

\section{Vaccination}

Preterm babies should be vaccinated according to the recommended Yes schedule, without correction for prematurity

\section{Jaundice}

When a newborn baby shows signs of jaundice, the doctor performs a Yes physical examination and blood tests to help determine the cause and treatment

When severe jaundice goes untreated for too long, it can cause a condition of Yes brain damage

\section{Temperature regulation}

Keeping your home warm enough and making sure the newborn is dressed Yes right is necessary

\section{Umbilical cord care}

Keep the stump dry, sticking with sponge baths, and letting the stump fall off Yes on its own is necessary

Signs of infection and active bleeding of the umbilical cord stump can result Yes in omphalitis 